\title{
Pharmaceutical Regulatory Affairs: Open Access
}

\section{Negative Effects of Addiction}

\section{Bassam Abdul Rasool Hassan*}

Clinical Pharmacy Discipline, School of Pharmaceutical Sciences, University of Sains Malaysia, Malaysia

\section{Introduction}

Addiction is a condition that results when a person ingests or continues using a substance which leads to changing of the mood or behavior. These days the term of addiction does not include addiction to substances such as alcohol or cocaine or nicotine but it has expands to include addiction to computer, video games, exercise abuse, pornography and gambling. As a result of that the addicted people will lose control on their talking, behaving and using, moreover their addiction may reach to harmful point i.e., death.

\section{Negative Effect on Health}

Addiction potentially has devastate effects on person health, since the addiction on drugs may leads to HIV infection, stroke, cardiovascular disease, bacterial endocarditis, hepatitis, malnutrition and respiratory infections and a host of related maladies. Moreover, drug addiction will also associated with the increases in incidence of specific types of cancers depending on the type of the drug to which the person is addicted.

\section{Negative Effect on Life (Emotion, Psychology, Relationships and Family)}

Addiction also has a dramatic effect on addict people emotions and lives, since drug addiction leads to depression, change in hobbies, behavior, thoughts, relationships with friends, disrupt personality, lost of concentration and memory, increases aggressive actions, poor performance in different sections, make person drowsy and it will also affect on their income i.e., financial situation.

\section{Conclusion}

As it is clear from the above points the effects of addiction on human health are critical and in several cases, deadly. Therefore it is a very important point for the open access journals to encourage researchers and clinicians to work hard in order to clarify the main side effects and diseases that caused by and/ or associated with different types of addictions. So by this way they will give the addicted people the motivation to quit from addiction, not only to protect them but also to protect their families from the critical side effects of addiction.
*Corresponding author: Bassam Abdul Rasool Hassan, Clinical Pharmacy Discipline, School of Pharmaceutical Sciences, University of Sains Malaysia, 11800, Minden, Penang, Malaysia, Tel: (+6)016-423-0950; Email: bassamsunny@yahoo.com

Received October 09, 2012; Accepted October 10 2012; Published October 12 2012

Citation: Hassan BAR (2012) Negative Effects of Addiction. Pharmaceut Reg Affairs 1:e113. doi:10.4172/2167-7689.1000e113

Copyright: ( $) 2012$ Hassan BAR. This is an open-access article distributed under the terms of the Creative Commons Attribution License, which permits unrestricted use, distribution, and reproduction in any medium, provided the original author and source are credited. 